\title{
Hip Circumference
}

National Cancer Institute

\section{Source}

National Cancer Institute. Hip Circumference. NCI Thesaurus. Code C100947.

A circumferential measurement of the largest part of the hip. 